\title{
Relevance of asbestos bodies in sputum
}

\author{
H. Teschler, A.B. Thompson, R. Dollenkamp, N. Konietzko, U. Costabel
}

Relevance of asbestos bodies in sputum. H. Teschler, A.B. Thompson, R. Dollenkamp, N. Konietzko, U. Costabel. (C)ERS Journals Ltd 1996.

ABSTRACT: The presence of asbestos bodies (ABs) in sputum specimens of individuals with occupational asbestos exposure has been well-documented. The aim of this study was to determine their clinical relevance in comparison to the concentration of $\mathrm{AB}$ in bronchoalveolar lavage (BAL) and lung tissue.

Subjects were included following a well-documented exposure of asbestos history $(n=93)$ or BAL fluid analysis positive for $\mathrm{ABs}(\mathrm{n}=42)$. The subjects with a well documented history of $\mathrm{AB}$ exposure were divided into three groups: heavy (Group 1, $n=29$ ); moderate (Group 2, $n=31$ ); or occasional exposure (Group 3, $n=33$ ). BAL fluid was available from all subjects, and lung tissue from 21 subjects. To assess the variability, 10 sputum positive subjects collected subsequent sputum on days 2 , 7, 14, 30 and 90. ABs were determined by light microscopy after membrane filtration of specimen digests.

The mean sputum AB content was highest in Group $1\left(2.4 \pm 5.5 \mathrm{AB} \cdot \mathrm{mL}^{-1}\right)$, lower in Group $2\left(0.2 \pm 0.3 \mathrm{AB} \cdot \mathrm{mL}^{-1}\right)$ and lowest in Group $3\left(0.1 \pm 0.1 \mathrm{AB} \cdot \mathrm{mL}^{-1}\right)$ suggesting a correlation with cumulative exposure. However, many negative sputum samples were noted, when BAL specimens were positive. The AB content of sputum and BAL specimens did not correlate. ABs were found in sputum of all subjects with a tissue content of $>1,000 \mathrm{AB} \cdot \mathrm{cm}^{-3}$, but in none with contents of $<1,000 \mathrm{AB} \cdot \mathrm{cm}^{-3}$. Substantial variability of $\mathrm{ABs}$ was found in the five sequentially collected sputa of 10 initially positive patients (coefficient of variation $28-93 \%$ ), but only two false negatives were found in these 50 samples.

Thus, sputum analysis for asbestos bodies is an insensitive method for assessing the lung asbestos burden, much less sensitive than bronchoalveolar lavage fluid analysis. However, a sputum sample positive for asbestos bodies is suggestive of a high lung asbestos burden.

Eur Respir J., 1996, 9, 680-686.
Ruhrlandklinik, Depts of Pneumology and Allergy, Medical Faculty, University of Essen, Federal Republic of Germany.

\author{
Correspondence: H. Teschler \\ Ruhrlandklinik \\ Tüschener Weg 40 \\ D-45239 Essen \\ Germany
}

Keywords: Asbestos bodies bronchoalveolar lavage

lung tissue

sputum

Received: July 191994

Accepted after revision August 151995

Grant support was received from Arbeitsgemeinschaft zur Förderung der Pneumologie an der Ruhrlandklinik (AFPR).
Asbestos exposure is recognized to occur in most industrialized countries as a result of occupational or environmental sources $[1,2]$. Asbestos bodies (ABs) are a hallmark of asbestos exposure in the human lung [3], and an important component of the histological diagnosis of asbestos-induced lung diseases $[4,5]$. When lung digestion techniques are utilized, small numbers of $\mathrm{ABs}$ are found in the lungs of more than $90 \%$ of the general population $[3,5]$, but much higher quantities are found in lungs of occupationally asbestos-exposed subjects [3-6]. The vast majority of ABs isolated from the human lungs are formed on long amphiboles [7]. Thus, they appear to be a valuable indicator of past exposure to amphibole asbestos.

ABs are sufficiently large to be detectable by light microscopy. In histological sections, ABs may be demonstrated either embedded within the lung interstitium, or within the bronchoalveolar spaces $[5,8]$. ABs deposited in the airspace compartment are accessible to bronchoalveolar lavage (BAL) [9-11], and may be found in sputum specimens from occupationally-exposed subjects [12-17].

If asbestos-related disease is suspected, diagnosis requires quantitative information on past asbestos exposure, which can often be obtained through the occupational history. However, some patients present with only limited information on past asbestos exposure. The lung content of $\mathrm{ABs}$ is proportional to cumulative exposure $[3,5]$, but quantitation of lung $\mathrm{ABs}$ requires surgical lung biopsy. In order to avoid the necessity of a surgical procedure, attention has turned from quantification of $\mathrm{ABs}$ in lung tissue $[3,6]$, if to BAL $[9-11,18]$ or sputum specimens $[12-17,19]$ as the means for establishing the exposure history.

BAL is less invasive than open lung biopsy, but only enables collection of intra-alveolar ABs. Several careful investigations, however, have demonstrated a reasonably good correlation of $\mathrm{AB}$ concentrations in $\mathrm{BAL}$ fluid with the degree of asbestos exposure and the $\mathrm{AB}$ burden of the lung [20-22]. Discrepant results in primarily chrysotileexposed asbestos workers indicate that the type of asbestos exposure (amphibole versus chrysotile) might markedly alter this relationship [9]. Collection of sputum is simpler, less invasive, and less expensive than BAL. The presence of $\mathrm{ABs}$ in sputum is felt to be a highly specific marker of asbestos exposure, and indicative of a considerable asbestos load within the lung [12-14]. However, 
sputum $\mathrm{AB}$ quantification appears to be an insensitive measure of lung asbestos burden. Moreover, the correlation between $\mathrm{BAL}$ and sputum $\mathrm{AB}$ content is not wellestablished.

The main objectives of this study, therefore, were, 1) to compare the $\mathrm{AB}$ concentration in sputum and $\mathrm{BAL}$ fluid with each other and with the degree of occupational asbestos exposure; 2) to compare $\mathrm{AB}$ counts in sputum with the concentrations in the lung tissue from a subset of subjects who underwent lung biopsy; and 3) to evaluate the variability of $A B$ counts in sequential sputum specimens from individuals with documented occupational exposure to asbestos.

\section{Methods}

\section{Study population}

The study population consisted of 135 subjects (115 males and 20 females; mean age $61 \pm 7$ yrs) with a wide range of occupational exposures to mixed asbestos dust, in whom BAL was performed for suspicion of asbestosrelated disease and who were able to produce sputum. Patients with a febrile respiratory infection were excluded. During their stay in hospital, medical and occupational histories were obtainable from 93 of the subjects. According to these exposure and job data, these 93 subjects were classified into three groups (table 1): Group 1 consisted of subjects who had worked in high exposure settings ( $>6$ months, $8 \mathrm{~h} \cdot \mathrm{day}^{-1}$ ) as asbestos textile workers, insulators or welders; Group 2 included subjects who had moderate occupational asbestos exposure ( $>6$ months, $<4$ h.day $^{-1}$ ) as welders, mechanical-repairers, sheet-metal workers, electricians or foundry workers; and Group 3 consisted of subjects who had occasional asbestos exposure.

The variability of sputum $\mathrm{AB}$ counts was determined in 10 subjects ( 9 males and 1 female; mean age $57 \pm 8$ yrs). These subjects were all cigarette smokers and met the American Thoracic Society (ATS) criteria for chronic

Table 1. - Demographic and exposure data for the three study groups

\begin{tabular}{lccc}
\hline & Group 1 & Group 2 & Group 3 \\
\hline Pts n & 33 & 31 & 29 \\
Sex F/M & $8 / 25$ & $4 / 27$ & $5 / 24$ \\
Age yrs* & $59 \pm 6$ & $61 \pm 7$ & $61 \pm 8$ \\
Smoking habits & & & \\
Never n & 9 & 7 & 8 \\
Former n & 18 & 17 & 16 \\
Current n & 6 & 7 & 5 \\
Asbestos exposure* & & & \\
Duration yrs & $10 \pm 6$ & $7 \pm 5$ & - \\
Time since last exposure yrs & $13 \pm 8$ & $16 \pm 8$ & - \\
\hline
\end{tabular}

Pts: patients; M: male; F: female; Group 1: subjects who had worked in a high exposure setting ( $>6$ months, 8 h·day ${ }^{-1}$ ); Group 2: subjects who had moderate occupational asbestos exposure ( $>6$ months, $<4$ h.day ${ }^{-1}$ ); Group 3: subjects who had occasional asbestos exposure. *: mean \pm SD. bronchitis [23], with daily productive cough. The subjects were selected from individuals with sputum positive for ABs. Sputum was collected on days 1, 2, 7, 14, 30 and 90, and processed as described.

All subjects gave informed consent to BAL and, if clinically indicated, to lung biopsy or lung resection. Open lung biopsy $(n=9)$ was performed for diagnosis of interstitial lung disease, and lung resection $(n=12)$ for the surgical treatment of lung carcinoma. Written consent was obtained according to institutional guidelines.

\section{Bronchoalveolar lavage}

Bronchoscopy and BAL were carried out according to previously described procedures [24]. The BAL was routinely performed in a segment of the right middle lobe. However, in 21 patients undergoing open lung biopsy $(n=15)$ or lobectomy $(n=6)$ the lobe chosen for BAL was determined by the site of the intended surgical biopsy or lung resection. A total of $100 \mathrm{~mL}$ of $0.9 \%$ saline was instilled in five $20 \mathrm{~mL}$ aliquots, and gentle suction was applied after each instillation. The recovered fluid was pooled prior to analysis and the volume measured. For $\mathrm{AB}$ counting, an aliquot of $10 \mathrm{~mL}$ was taken from the native BAL fluid. The remaining fluid was filtered through surgical gauze. Total cell counts were determined using a Neubauer counting chamber. In addition, a trypan blue exclusion test for cell viability was performed.

The $10 \mathrm{~mL}$ of native BAL fluid were mixed with 100 $\mathrm{mL}$ distilled water and then allowed to incubate for at least $1 \mathrm{~h}$ at room temperature to lyse cells. The mixture was vacuum filtered through a $0.45 \mu \mathrm{m}$ membrane filter (Millipore Corp., Bedford, MA, USA) after gentle agitation. The membrane was air-dried at room temperature and mounted onto a glass slide coated with Histokitt ${ }^{\circledR}$ (Karl Hecht GmbH, Sondheim, Germany). The membrane was subsequently covered with a second layer of Histokitt ${ }^{\circledR}$ and overlaid with a coverslip. After $24 \mathrm{~h}$, the Histokitt ${ }^{\circledR}$ had cleared the filter, allowing unobstructed visualization of the optically transparent $\mathrm{AB}$ core. ABs were counted by examining the entire area of the membrane under the light microscope at 400 fold magnification. Only yellow-brown bodies that fulfilled the morphological criteria given by CHURG and co-workers $[5,7]$ were considered to be ABs. The detection limit was $0.1 \mathrm{AB} \cdot \mathrm{mL}^{-1} \mathrm{BAL}$ fluid, since $10 \mathrm{~mL}$ of BAL fluid were filtered and $1 \mathrm{AB} \cdot$ filter $^{-1}$ was the minimum $\mathrm{AB}$ count. The concentrations were reported as $\mathrm{AB} \cdot \mathrm{mL}^{-1} \mathrm{BAL}$ fluid.

\section{Sputum}

Patients were asked to expectorate spontaneous, early morning sputum into a large plastic cup. Each sample was surveyed for the presence of a typical sol and gel phase, which was used to indicate that the material represented sputum of lung origin instead of spit. No microscopic examination of macrophages or epithelial cells was performed. On the first occasion, only $58 \%$ of the patients produced a satisfactory specimen. The remaining patients provided an appropriate morning specimen 
during a sampling period of 14 days. The volume was measured and the sputum sample then digested by $5.25 \%$ sodium hypochloride solution. The digestate was then filtered onto a $1.2 \mu \mathrm{m}$ membrane filter. The entire membrane was prepared for light microscopy analysis as described above. The results were given as $\mathrm{AB} \cdot \mathrm{mL}^{-1}$ sputum.

\section{Lung tissue}

From each patient $1 \mathrm{~cm}^{3}$ wet, formalin-fixed lung tissue was digested in $5.25 \%$ sodium hypochloride solution. After digestion was completed, the suspension was treated in an ultrasonic bath for $30 \mathrm{~s}$ and the residue filtered onto a $1.2 \mu \mathrm{m}$ membrane filter. The membrane was processed and $\mathrm{ABs}$ were counted as described above. The results were reported as $\mathrm{AB} \cdot \mathrm{cm}^{-3}$ wet lung tissue. A comparison between $\mathrm{AB}$ counts in wet and dry lung tissue was possible in six patients, and led to a conversion factor of $9.2\left(\mathrm{AB} \cdot \mathrm{g}^{-1}\right.$ dry lung tissue $=9.2 \times \mathrm{AB} \cdot \mathrm{cm}^{-3}$ wet lung tissue).

\section{Statistical methods}

Data were expressed as mean \pm SD. Group comparisons were made using the nonparametric Mann-Whitney U-test. The chi-squared test was utilized for comparing proportions in contingency tables. Spearman's correlation coefficient (r) was employed to evaluate the relationship between $\mathrm{AB}$ concentrations in sputum, BAL, and lung tissue. To measure agreement between sputum and BAL AB counts, a plot of the difference between the results of both techniques against the mean was applied [25]. The variability over time of $\mathrm{AB} \cdot \mathrm{mL}^{-1}$ sputum was expressed by the coefficient of variation, and counts for the sequential time periods were compared by analysis of variance (ANOVA). Statistical calculations were performed with the CSS Statistica package (StatSoft Inc., Tulsa, OK, USA) on a personal computer. Significance was defined as a pvalue less than 0.05 .

\section{Results}

\section{Demographic data}

Demographic data for the three exposure groups are listed in table 1. No significant difference was found with regard to mean age, sex distribution or smoking habits.

\section{Relationship between $A B$ counts, smoking habits and exposure history}

Sputum Ab counts $\left(\mathrm{n} \cdot \mathrm{mL}^{-1}\right)$ within each group were significantly higher in smokers (Group 1: 2.9 $\pm 4.7 \mathrm{vs}$ 1.9 $\pm 4.1, \mathrm{p}<0.01$; Group 2: $0.26 \pm 0.21$ vs $0.16 \pm 0.24$, $\mathrm{p}<0.05$; Group 3: $0.12 \pm 0.10$ vs $0.08 \pm 0.11, \mathrm{p}<0.05)$. A significant correlation was found between levels of ABs in sputum and time since last exposure (Group 1: $r=-0.34$, $\mathrm{p}<0.01$; Group 2: $\mathrm{r}=-0.42, \mathrm{p}<0.001)$ and duration of exposure (Group 1: $r=0.40, p<0.001$; Group 2: $r=0.31, p<0.001$ ). Reliable exposure data for Group 3 were not available.
Table 2. - Asbestos body counts in sputum and bronchoalveolar lavage (BAL) among sputum producing patients in the three study groups

\begin{tabular}{|c|c|c|c|}
\hline $\begin{array}{l}\text { Asbestos } \\
\text { bodies }\end{array}$ & $\begin{array}{c}\text { Group } \\
n=33\end{array}$ & $\underset{n=31}{\text { Group }} 2$ & $\begin{array}{c}\text { Group } \\
n=29\end{array}$ \\
\hline Sputum $\mathrm{n} \cdot \mathrm{mL}^{-1}$ & $\begin{array}{c}2.4 \pm 5.5 \\
(0.0-28.4)\end{array}$ & $\begin{array}{c}0.2 \pm 0.3 \\
(0.0-1.3)\end{array}$ & $\begin{array}{c}0.1 \pm 0.1 \\
(0.0-0.5)\end{array}$ \\
\hline $\mathrm{BAL} n \cdot \mathrm{mL}^{-1}$ & $\begin{array}{c}66 \pm 106 \\
(3.2-452)\end{array}$ & $\begin{array}{c}2.5 \pm 1.9 \\
(0.1-6.1)\end{array}$ & $\begin{array}{c}0.2 \pm 0.3 \\
(0.0-1.2)\end{array}$ \\
\hline
\end{tabular}

Data are presented as mean $\pm \mathrm{SD}$, and range in parenthesis. Comparison between groups: $\mathrm{p}<0.01$, Group 2 vs Group 3; $\mathrm{p}<0.05$, all other group comparisons. For description of groups see legend to table 1 .

$\mathrm{AB}$ counts both in sputum and BAL were compared among the subject groups (table 2). The number of ABs both in sputum and BAL was related to exposure history, and was statistically significantly higher in Group 1 compared to Groups 2 and 3 ( $\mathrm{p}<0.01)$; and also in Group 2 compared to Group $3(\mathrm{p}<0.05)$. However, all groups included subjects who had no ABs found in their sputum. In contrast, all members of Groups 1 and 2 had ABs in their BAL fluid. As a result, $33 \%$ of subjects in Group 1, 68\% of subjects in Group 2, and 45\% of subjects in Group 3 had BAL AB, but not sputum $A B$. No subjects without $A B s$ in BAL fluid had $A B$ in sputum (table 3).

\section{Comparison of BAL fluid and sputum $A B$ content}

In the study population of 135 patients, the sputum content of ABs ranged 0-28.4 $(0.6 \pm 2.9) \mathrm{AB} \cdot \mathrm{cm}^{-3}$. The BAL content of AB ranged 0-451.7 (16.9 \pm 58.9 ) $\mathrm{AB} \cdot \mathrm{cm}^{-3}$. Figure 1a shows the percentage of negative sputum specimens and figure $1 \mathrm{~b}$ the $\mathrm{AB}$ concentrations of the subjects grouped by $\mathrm{BAL} \mathrm{AB}$ concentrations. The ranges of $\mathrm{AB}$ for each group were: $0(n=30) ; 0.1-0.4$ $(\mathrm{n}=33) ; 0.5-0.9(\mathrm{n}=13) ; 1.0-4.9(\mathrm{n}=26) ; 5.0-49.9(\mathrm{n}=23)$; and $>50(\mathrm{n}=10) \mathrm{AB} \cdot \mathrm{mL}^{-1}$ BAL fluid.

As shown in figure 1a, a large percentage of sputum samples from subjects with ABs in their BAL fluid contained no ABs. This was true even for some subjects with a high number of ABs in their BAL fluid. As can be seen in figure $1 \mathrm{~b}$, sputum analysis considerably

Table 3. - Number of sputum producing patients with positive and/or negative sputum and bronchoalveolar lavage (BAL) samples among the three study groups

\begin{tabular}{|c|c|c|c|}
\hline & $\underset{n=33}{\text { Group }} 1$ & $\underset{n=31}{\text { Group } 2}$ & $\begin{array}{c}\text { Group } \\
n=29\end{array}$ \\
\hline +ve Sputum & $22(67)$ & 7 (23) & $5 \quad(17)$ \\
\hline +ve BAL & $33(100)$ & 28 (90) & $18 \quad(62)$ \\
\hline $\begin{array}{l}\text {-ve Sputum } \\
\text { +ve BAL }\end{array}$ & 11 (33) & 21 & $13 \quad(45)$ \\
\hline $\begin{array}{l}\text { +ve Sputum } \\
\text {-ve BAL }\end{array}$ & $0 \quad(0)$ & $0 \quad(0)$ & $0 \quad(0)$ \\
\hline
\end{tabular}

Values in parenthesis are percentages. For description of groups see legend to table 1 . 
a)

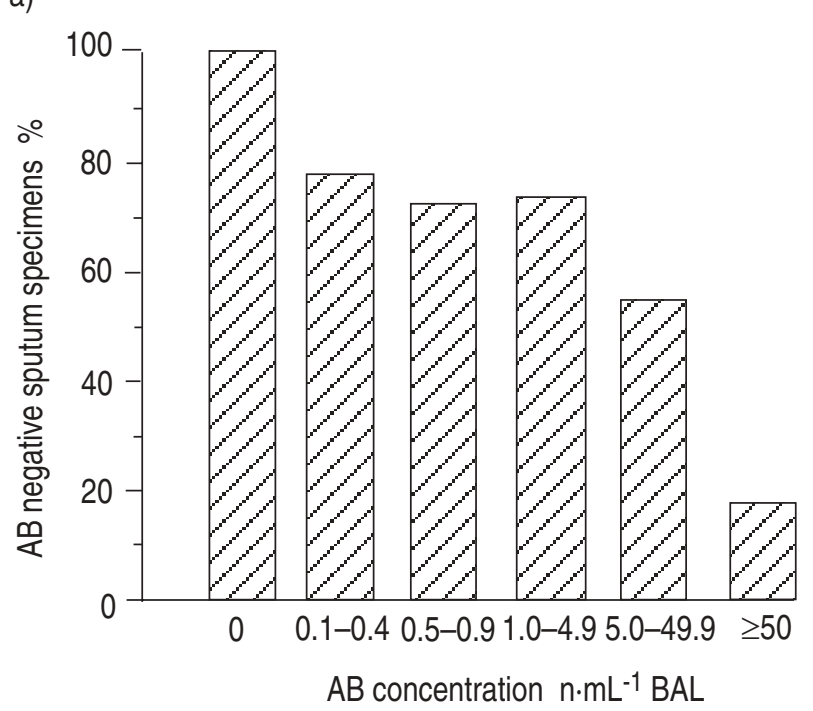

b)

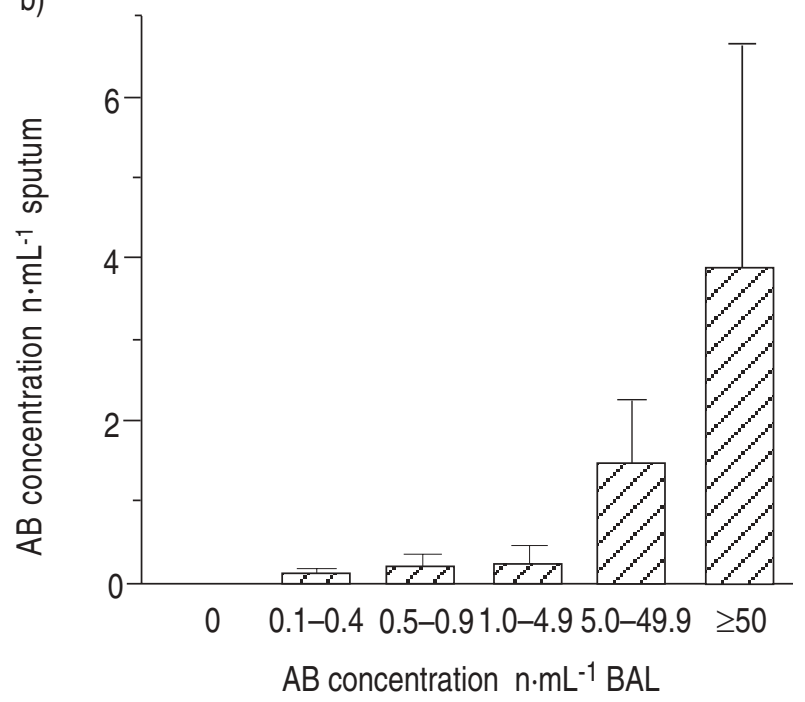

Fig. 1. - a) Percentage of asbestos body (AB) negative sputum samples and b) concentration of $\mathrm{ABs}$ in sputum for different ranges of $\mathrm{AB}$ concentrations in bronchoalveolar lavage (BAL). Data show mean \pm SD.

under-estimated the concentration of $\mathrm{ABs}$ in BAL fluid. Comparison of the $\mathrm{AB}$ content of BAL fluid and sputum demonstrated no significant correlation $(r=0.13$, $\mathrm{p}=0.34$ ), either for the entire study population, the three exposure groups $(r=0,27,0,17,0,19$ for the groups with high, moderate and occasional exposure, respectively), or for the five subgroups with positive $A B$ counts in the BAL fluid.

Plotting the data as the difference between the $\mathrm{AB}$ counts in sputum and BAL fluid versus the mean value for the two sampling procedures, allowed for analysis of sampling bias [25]. Plotted in this fashion (fig. 2), the data demonstrate that the recovery of $\mathrm{ABs}$ by sputum is systematically lower than the number recovered by BAL fluid (mean $=-8.2 \pm 4.9 \mathrm{AB} \cdot \mathrm{mL}^{-1}, 95 \%$ confidence limits $(95 \% \mathrm{CI})-3.3$ to $\left.-13.1 \mathrm{AB} \cdot \mathrm{mL}^{-1}\right)$. There was a linear increase in the difference between the two sampling methods as the BAL content of $\mathrm{AB}$ increased, reflecting

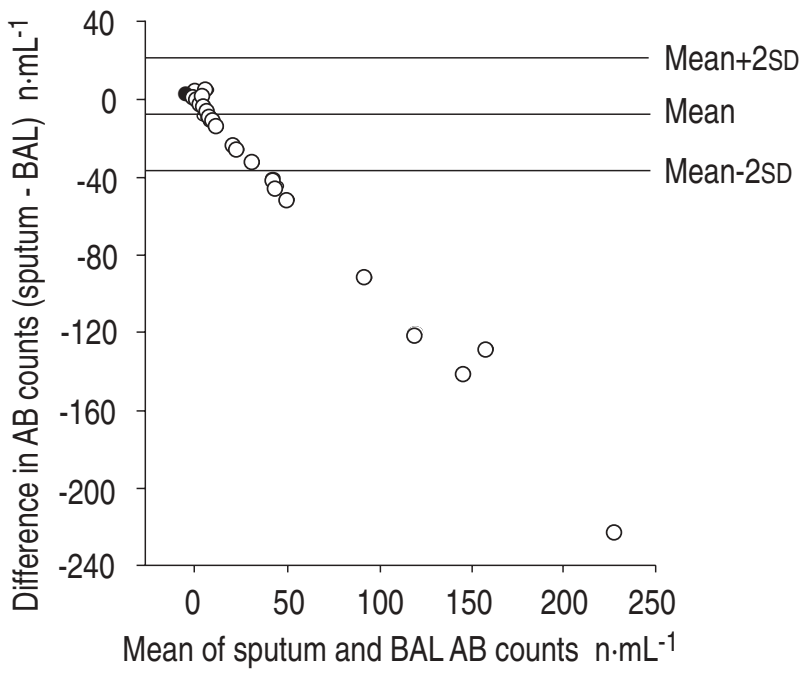

Fig. 2. - Difference between asbestos body (AB) counts in sputum and bronchoalveolar lavage (BAL) fluid versus the mean of the counts.

very low recovery rates by sputum, particularly in those individuals with high $\mathrm{AB}$ counts in BAL fluid.

\section{Comparison of tissue and sputum $A B$ content}

Analysis of the open lung biopsy specimens revealed ABs in all samples. The number of ABs ranged 12-44,000 (mean \pm SD 6,811 $\pm 10,796) \mathrm{AB} \cdot \mathrm{cm}^{-3}$ wet lung tissue (fig. 3). For subjects with less than $1,000 \mathrm{AB} \cdot \mathrm{cm}^{-3}$ of wet lung tissue, no $\mathrm{ABs}$ were found in the sputum samples. In contrast, all subjects with asbestos counts greater than $1,000 \mathrm{AB} \cdot \mathrm{cm}^{-3}$ of wet lung tissue had $\mathrm{ABs}$ in their sputum. However, in the 11 subjects with $\mathrm{ABs}$ in their sputum there was no correlation with the number of $\mathrm{ABs}$ in the lung biopsy specimens $(r=0.26, p=0.34)$.

\section{Variability of sputum $A B$ counts over time}

In the initial positive sputum samples, used as the criteria for enrolling subjects in this part of the investigation,

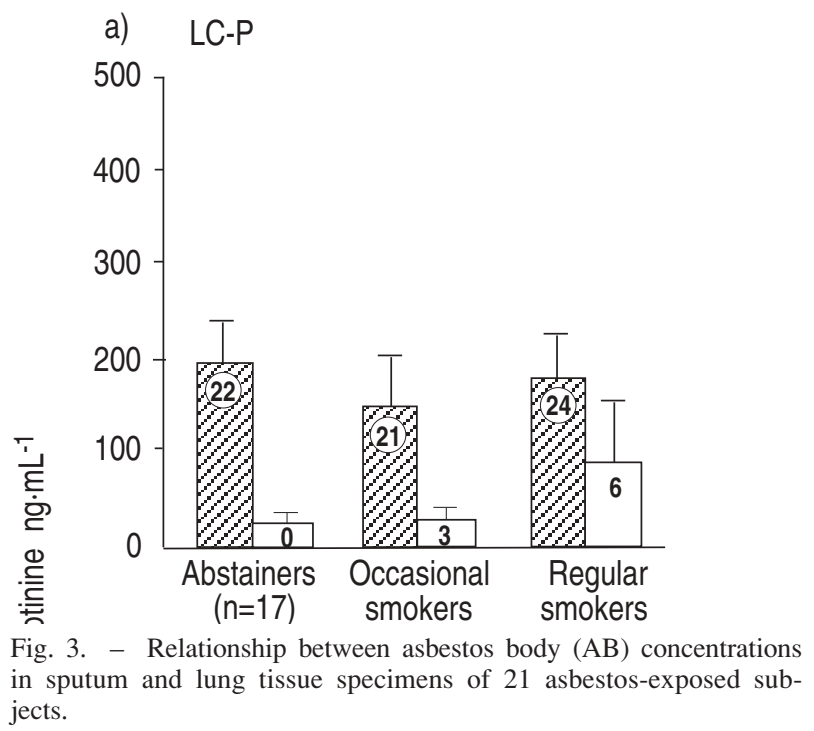


Table 4. - Variability of asbestos body counts $\left(n \cdot \mathrm{mL}^{-1}\right)$ in subsequent sputum specimens of 10 subjects

\begin{tabular}{rrrrrrrrr}
\hline $\begin{array}{l}\text { Subject } \\
\text { No. }\end{array}$ & Day 1 & Day 2 & Day 7 & Day 14 & Day 30 & Day 90 & $\begin{array}{c}\text { Mean } \\
\text { count }\end{array}$ & $\begin{array}{c}\text { CoV } \\
\%\end{array}$ \\
\hline 1 & 14.0 & 10.0 & 18.0 & 11.0 & 21.0 & 16.0 & 15.0 & 28 \\
2 & 2.4 & 0.6 & 5.0 & 3.1 & 0.2 & 2.5 & 2.3 & 76 \\
3 & 2.8 & 0.0 & 8.0 & 6.3 & 12.0 & 3.1 & 5.4 & 80 \\
4 & 0.2 & 0.4 & 0.0 & 0.3 & 0.6 & 0.2 & 0.3 & 71 \\
5 & 5.8 & 2.6 & 3.9 & 7.8 & 1.3 & 5.2 & 4.4 & 53 \\
6 & 18.0 & 56.0 & 12.0 & 29.0 & 34.0 & 2.6 & 25.3 & 75 \\
7 & 0.3 & 1.9 & 4.0 & 0.7 & 0.2 & 2.9 & 1.7 & 93 \\
8 & 2.9 & 0.3 & 0.7 & 1.8 & 1.5 & 3.2 & 1.7 & 67 \\
9 & 0.3 & 1.4 & 3.1 & 1.0 & 0.6 & 4.2 & 1.8 & 87 \\
10 & 8.7 & 0.1 & 12.0 & 9.0 & 2.5 & 4.9 & 6.2 & 72 \\
\hline
\end{tabular}

CoV: coefficient of variation.

the sputum content of $\mathrm{ABs}$ ranged $0.2-18 \mathrm{AB} \cdot \mathrm{mL}^{-1}$ sputum (table 4). In the subsequent 50 samples of sputum, only two were found to contain no $\mathrm{ABs}$, suggesting that sputum positive for $\mathrm{ABs}$ was a consistent finding. ANOVA suggested that the $\mathrm{AB}$ counts in the sputum samples did not differ over time $(\mathrm{p}=0.98)$. However, the coefficient of variation of the sequential counts ranged 28-92\%, demonstrating that the quanti-fication of lung asbestos burden by sampling sputum introduces significant variability.

\section{Discussion}

The results of this study suggest that quantification of ABs in sputum, whilst related to history of occupational asbestos exposure, is less sensitive than BAL for the assessment of the lung asbestos body content. Furthermore, a significant percentage of the subjects, all of whom had asbestos exposure, had negative sputum analyses. Thus, analysis of sputum for ABs is an insensitive indicator of exposure. However, the data from the open lung biopsies would suggest that the presence of $\mathrm{ABs}$ in sputum indicates a relatively heavy asbestos burden in the lung of the subject under investigation.

These results are similar to previous reports of sputum analysis for $\mathrm{ABs}$ in occupationally-exposed subjects. In one report $35 \%$, and in another $29 \%$, of heavily exposed subjects were found to have sputum positive for ABs $[12,26]$. According to our results, smokers are more likely to produce a satisfactory sputum sample with higher asbestos body counts than former or nonsmokers. In agreement with this, it has been demonstrated that smokers appear to have higher lung asbestos body burden than nonsmokers, probably due to a higher retention on the basis of an impaired clearance $[27,28]$. The number of $\mathrm{ABs}$ present in the sputum correlated both with interval since last exposure and duration of exposure. This is in agreement with previous investigations [12, 27], and indicates that cumulative exposure is the significant factor in relation to the occurrence and amount of $A B$ in sputum. In two other reports, sputum analysis yielded positive findings of $\mathrm{ABs}$ only if the lung content of $\mathrm{ABs}$ was higher than $900 \mathrm{AB} \cdot \mathrm{g}^{-1}$ wet tissue or $1,000 \mathrm{AB} \cdot \mathrm{cm}^{-3}$, respectively $[13,29]$. This is in perfect agreement with our results and underlines that the occurrence of $\mathrm{ABs}$ in sputum is an exquisitely specific marker of heavy occupational exposure, mainly to amphiboles. However, $\mathrm{ABs}$ are generally a poor indicator of the pulmonary chrysotile asbestos burden and great variability exists in $\mathrm{AB}$ formation on longer amphibole fibres [3-5, 9]. Recent studies suggest that detection of uncoated asbestos fibres in digested sputum specimens by means of electron microscopy is a more sensitive way of confirming chrysotile and total asbestos exposure [15, 19].

The specificity of sputum ABs as an indicator of occupational asbestos exposure was not addressed by the investigation, as the subjects did not include a group of occupationally-unexposed individuals. This issue has been addressed in a previous publication [30]. In cytology specimens from 11,000 patients processed by a cytology laboratory, there were only five samples positive for $\mathrm{ABs}$, and all of these were in retrospect found to be from subjects with significant occupational exposures.

BAL has been investigated as a means for quantifying the lung content of ABs [9-11, 18]. Previous investigations have demonstrated that there is a statistically significant correlation between $\mathrm{BAL}$ fluid $\mathrm{AB}$ content and lung $\mathrm{AB}$ content. It has been shown that the finding of $1 \mathrm{AB} \cdot \mathrm{mL}^{-1}$ of $\mathrm{BAL}$ fluid roughly correlates with a tissue concentration of $1,000 \mathrm{AB} \cdot \mathrm{g}^{-1}\left(\mathrm{or} \mathrm{cm}^{-3}\right)$ lung tissue [20-22]. In the current study, sputum AB counts were found not to correlate with BAL counts. Furthermore, many subjects with positive BAL fluid analysis had negative sputum results. These findings suggest that BAL is the superior of the two methods for assessing lung $\mathrm{AB}$ content.

The high coefficient of variation of the $A B$ counts made on sequential sputum samples underscores the poor accuracy of lung $\mathrm{AB}$ quantification by sputum analysis. These results are similar to those reported previously in an analysis of sputa from 20 subjects, sampled over seven consecutive days [26]. This earlier report differs in the timing of the collections (over 1 week versus over 3 months) and in that some of the subjects had very high sputum $\mathrm{AB}$ counts (up to $2,458 \mathrm{AB} \cdot \mathrm{mL}^{-1}$ ), but very similar variations were noted in sputum $A B$ counts. Importantly, many more "false negatives" were reported. The majority of the subjects had at least one negative sputum in spite of previous positive sputa. This is in contrast to our results, in that only two of the 50 sequential sputa were negative.

The design of our study relied upon early morning collection of spontaneously expectorated sputum. It is 
possible that the use of induced sputum may have yielded fewer false negatives.

Inducing sputum has been reported to significantly increase the number of positive specimens and the concentration of ABs [31, 32]. However, the improvement was far lower than would be necessary to significantly improve the correlation between BAL and sputum $\mathrm{AB}$ counts noted here. The subjects for the study of the variability of sequential sputum $\mathrm{AB}$ counts were chosen for the ability to produce sputum on a daily basis. This could potentially bias the result of the analysis as daily expectoration of sputum could conceivably alter $\mathrm{AB}$ clearance from the lower respiratory tract. Another potential limitation concerns the issue of whether sputum or spit was collected. This determination was based on the macroscopic appearance of the expectorated material instead of a microscopic examination of cells.

In conclusion, sputum analysis for asbestos bodies would appear to be an insensitive method for estimating lung asbestos body load. A negative sputum analysis for asbestos bodies in no way excludes the possibility of a high lung asbestos burden. However, a sputum sample positive for asbestos bodies suggests a significant lung burden of asbestos. Bronchoalveolar lavage would appear to be a superior nonsurgical method of sampling the lung for evidence of asbestos exposure.

Acknowledgements: The authors thank K-M. Müller and M. Fischer, Institute of Pathology, Berufsgenossenschaftliche Krankenanstalten "Bergmannsheil", University of Bochum, for performing the lung tissue asbestos body analysis.

\section{References}

1. Rey F, Boutin C, Steinbauer J, et al. Environmental pleural plaques in an asbestos exposed population of north east Corsica. Eur Respir J 1993; 6: 978-982.

2. Jarvholm B, Larsson S, Hagberg S, Olling S, Ryd W, Toren K. Quantitative importance of asbestos as a cause of lung cancer in a Swedish industrial city: a casereferent study. Eur Respir J 1993; 6: 1271-1275.

3. Roggli VL. Human disease consequences of fiber exposure: a review of human lung pathology and fiber burden data. Environ Health Persp 1990; 88: 295-303.

4. Craighead JE, Abraham JL, Churg A, et al. The pathology of asbestos-associated diseases of the lungs and pleural cavities: diagnostic criteria and proposed grading schema. Arch Pathol Lab Med 1982; 106: 544-597.

5. Churg A, Green FHY. Pathology of occupational lung disease. New York, Tokyo, Igaku-Shoin, 1988; pp. 1397.

6. Ashcroft T, Heppleston AG. The optical and electron microscopic determination of pulmonary asbestos fibre concentration and its relation to the human pathological reaction. J Clin Pathol 1973; 26: 224-234.

7. Churg A, Warnock ML. Asbestos and other ferruginous bodies: their formation and clinical significance. $A m J$ Pathol 1981; 102: 447-456.

8. Roggli VL. Pathology of human asbestosis: a critical review. In: Fenoglio-Preiser CM, ed. Advances in Pathology. 2nd Edn. New York, Chicago, Year Book Medical Publisher, 1993.

9. Schwartz DA, Galvin JR, Burmeister LF, et al. The clinical utility and reliability of asbestos bodies in bronchoalveolar fluid. Am Rev Respir Dis 1991; 144: 684688.

10. De Vuyst P, Jedwab J, Dumortier P, Vandermoten G, Vande Weyer R, Yernault JC. Asbestos bodies in bronchoalveolar lavage. Am Rev Respir Dis 1982; 126: 972-976.

11. Teschler H, Konietzko N, Schoenfeld B, Ramin C, Schraps T, Costabel U. Distribution of asbestos bodies in the human lung as determined by bronchoalveolar lavage. Am Rev Respir Dis 1993; 147: 1211-1215.

12. Farley ML, Greenberg SD, Shuford EH Jr, Hurst GA, Spivey CG, Christianson CS. Ferruginous bodies in sputa of former asbestos workers. Acta Cytol 1977; 21: 693-700.

13. Roggli VL, Greenberg SD, McLarty JW, et al. Comparison of sputum and lung asbestos body counts in former asbestos workers. Am Rev Respir Dis 1980; 122: 941-945.

14. Roggli VL, McLarty JW, Greenberg SD. AB in sputum: a clinical marker of exposure. J Occup Med 1983; 25: 508.

15. Heller DS, Gordon RE. Demonstration of asbestos fibres in a ten year old sputum sample. Am J Ind Med 1991; 20: 415-419.

16. Bignon J, Depierre A, Bonnaud G, Goni J, Brouet G. Mise en evidénce des corps ferrugineux par microfiltration de l'expectoration. Nouv Presse Méd 1973; 2: 1697-1700.

17. Sebastien P, Bignon J, Izzetin Barris Y, Awad L, Petit G. Ferruginous bodies in sputum as an indication of exposure to airborne mineral fibres in the mesothelioma villages of Cappadocia. Arch Environ Health 1984; 39 : $18-23$.

18. Costabel U, Donner CF, Haslam PL, et al. Occupational lung diseases due to the inhalation of inorganic dust. Eur Respir J 1990; 3: 946-949.

19. Dodson RF, Williams MG Jr, Corn CJ, Idell S, McLarty JW. Usefulness of combined light and electron microscopy: evaluation of sputum samples for asbestos to determine past occupational exposure. Mod Pathol 1989; 2: 320-322.

20. Sebastien P, Armstrong B, Monchaux G, Bignon J. Asbestos bodies in bronchoalveolar lavage fluid and in lung parenchyma. Am Rev Respir Dis 1988; 137: 75-78.

21. De Vuyst P, Dumortier P, Moulin E, et al. Asbestos bodies in bronchoalveolar lavage reflect lung asbestos body concentration. Eur Respir J 1988; 1: 362-367.

22. Teschler H, Hoheisel G, Fischer M, Müller KH, Konietzko N, Costabel U. Asbestkörperchengehalt der bronchoalveolären Lavageflüssigkeit als Parameter einer erhöhten Asbestbelastung der Lunge. Dtsch Med Wschr 1993; 118: 1749-1754.

23. American Thoracic Society. Standards for the diagnosis and care of patients with chronic pulmonary obstructive disease (COPD) and asthma. Am Rev Respir Dis 1987; 136: 225-245.

24. Costabel U, Bross KJ, Matthys H. The immunoperoxidase slide assay: a new method for the demonstration of surface antigens on bronchoalveolar cells. Bull Eur Physiopathol Respir 1985; 21: 381-387.

25. Bland JM, Altman DG. Statistical methods for assessing agreement between two methods of clinical measurement. Lancet 1986; 8: 307-310.

26. McDonald JC, Sebastien P, Case B, McDonald AD, Dufresne A. Ferruginous body counts in sputum as index of past exposure to mineral fibres. Ann Occup Hyg 1992; 36: 271-282. 
27. McLarty JW, Greenberg SD, Hurst GA, et al. The clinical significance of ferruginous bodies in sputa. $J$ Occup Med 1980; 22: 92-96.

28. Churg A, Warnock ML. Correlation of quantitative asbestos body counts and occupation in urban patients. Arch Pathol Lab Med 1977; 101: 629-634.

29. Bignon J, Goni J, Bonnaud G, Jaurand MC, Dufour G, Pinchon MC. Incidence of pulmonary ferruginous bodies in France. Environ Res 1970; 3: 430-442.

30. Modin BE, Greenberg SD, Buffler PA, Lockhart JA,
Seitzman LH, Awe RJ. Asbestos bodies in a general hospital/clinic population. Acta Cytol 1982; 26: 667-677.

31. McLarty JW, Greenberg SD, Hurst GA, Spivey CG, Farley ML, Mabry LC. Statistical comparison of aerosolized induced and spontaneous sputum specimens in the Tyler Asbestos Workers Program. Acta Cytol 1980; 24: 460465.

32. Greenberg SD, Hurst GA, Matlage WT, Miller JM, Hurst IJ, Mabry LC. Tyler Asbestos Workers Program. Ann NY Acad Sci 1976; 271: 353-364. 


\section{Notes for Author}

1. Table 1. - Population numbers appear to be 17 female, 76 male $=93$. However, initial study population was 135, 125 male and $\mathbf{1 0}$ female. Thus does the study include only the 93 with medical history - where did the extra females come from?

2. Results - When discussing smokers vs nonsmokers you refer to tables 1 and 2. However, neither table shows the results for ABs in smokers/non smokers. Thus you do not show the values - should those be in table 2 and not just a statistical value?

3. p-values for table 2 in text do not appear to correspond to p-values in text e.g. table Group 2 vs $3=\mathrm{p}<0.01$ but text states 2 vs $3 \mathrm{p}<0.05$. Please check.

4. ? Redraw figure 1 a to show negative correlation which is the point of the figure? - see mock up.

5. Figure 1 - Are you happy with the zero BAL asbestosis column?

6. Abstract states group 3 sputum AB $0.01 \pm 0.001$ and table 2 shows $0.1 \pm 0.1$. Please check. 